\title{
Water evaporation in silica colloidal deposits
}

\author{
Jorge Peixinho ${ }^{\mathrm{a}, 1, *}$, Grégory Lefèvre ${ }^{\mathrm{a}}$, François-Xavier Coudert ${ }^{\mathrm{a}}$, \\ and Olivier Hurisse ${ }^{\mathrm{b}}$ \\ ${ }^{a}$ Chimie-ParisTech $\mathscr{E}$ CNRS UMR 7575, 11 rue Pierre et Marie Curie, 75005 Paris, \\ France \\ ${ }^{b}$ EDF RED, Fluid Dynamics, Power Generation and Environment, 6 quai Watier, \\ 78401 Chatou, France
}

\begin{abstract}
The results of an experimental study on the evaporation and boiling of water confined in the pores of deposits made of mono-dispersed silica colloidal micro-spheres are reported. The deposits are studied using scanning electron microscopy, adsorption of nitrogen, and adsorption of water through attenuated total reflection-infrared spectroscopy. The evaporation is characterized using differential scanning calorimetry and thermal gravimetric analysis. Optical microscopy is used to observe the patterns on the deposits after evaporation. When heating at a constant rate and above boiling temperature, the release of water out of the deposits is a two step process. The first step is due to the evaporation and boiling of the surrounding and bulk water and the second is due to the desorption of water from the pores. Additional experiments on the evaporation of water from membranes having cylindrical pores and of heptane from silica deposits suggest that the second step is due to the morphology of the deposits.
\end{abstract}

\section{Introduction}

The boiling of water is an everyday experience and the boiling temperature of water at atmospheric pressure is a "fixed point" used to calibrate thermometers since the $18^{\text {th }}$ century [1]. However, boiling in confined spaces or in porous materials is a complex phenomenon due to the presence of walls.

\footnotetext{
${ }^{*}$ Corresponding author. E-mail address: jorge.peixinho@univ-lehavre.fr (J. Peixinho)

${ }^{1}$ Present address: Laboratoire Ondes et Milieux Complexes, Université du Havre et CNRS UMR 6294, 53 rue de Prony, 76600 Le Havre, France
} 
In heat exchangers and steam generators, particles settle and form porous deposits. The deposition process of particles depends on multiple factors including $\mathrm{pH}$ and surface roughness $[2,3]$. Understanding the effects of the deposits on evaporation and boiling of water represents an important issue for Électricité de France (EDF) because it causes a severe reduction in efficiency particularly in steam generators [4]. Here we mimic deposits using a model system made of mono-disperse silica particles and study evaporation and boiling of water confined in the pores of micro-spheres colloidal silica.

The liquid-vapour phase transition of water confined in porous materials is not well documented whereas there are several reports on melting and freezing using calorimetry $[5,6,7]$. In these studies, melting point depression, hysteretic behaviour between freezing and melting, and modification of the bulk structure are quantified for a range of pores, chemical compositions, etc. However, a limited number of experimental studies deals with evaporation of water in a porous media at temperatures around the boiling point.

A discussion of the phase change of liquid-vapor systems in porous media including capillary effects, thickness of the porous layer and superheating can be found in [8]. Several numerical models and simulations based on continuous equations for mass conservation, heat conduction, Darcy's law and phase transition rules $[9,10,11]$ are available. These models predict temperature and liquid saturation fields. Recently, a more detailed description of the interfaces has been obtained using lattice-gas dynamic mean field theory [12] and molecular dynamics [13]. Specifically, these studies reported the presence of microscopic liquid films moving ahead of the main flow depending on the dynamics of adsorption/desorption properties: viscosity ratio, wetting angle, chemical potential and morphology of the porous media. All previous models are qualitative and the purpose of this study is to provide quantitative data.

The laboratory experiments presented here exploit silica [14] because it is chemically inert, nontoxic, polar and stable for the range of temperatures considered in this study $\left(T<400^{\circ} \mathrm{C}\right)$. At room temperature, the desorption of water out of films of colloidal silica is associated with the formation of drying cracks $[15,16]$. At higher temperature, the evaporation rate is increased. Water droplets containing colloidal silica experience a complex evaporation kinetic [17]. Indeed, the droplets shrink. This indicates that some water flows outwards entraining particles. These particles accumulate close to the liquidvapour interface and form a shell. The subsequent behaviour depends on the mechanical properties of this shell. A loose shell favors water to evacuate. When water evacuates the shell accumulates particles, becomes elastic and 
buckles. However, if the shell becomes too tough, vapour develops under the heated crust and pressure builds up until large cracks form. The sharp temperature increase due to the formation of the shell can be predicted by heat and mass transfer models [17, 18, 19]. These models are based on diffusion and Darcy's law for the calculation of the pressure drop through the shell.

Here, we report experiments on the evaporation and boiling of water confined in the pores of colloidal silica. First, the model system is studied using scanning electronic microscopy and adsorption measurements. Secondly, calorimetry measurements are performed and the results are compared with water in membranes having cylindrical pores and heptane in the colloidal silica. Finally, it is suggested that the morphology of the material is essential to understand the boiling kinetics.

\section{Materials}

The deposits were made of mono-dispersed silica micro-spheres purchased as dilute particles suspensions from Granuloshop (France). Two sizes of particles: $179 \pm 8 \mathrm{~nm}$ or $1.16 \pm 0.05 \mu \mathrm{m}$ in diameter were used. A deposit was obtained by settling a particle suspension column above an aluminum crucible with a inner diameter of $5 \mathrm{~mm}$. After sufficient settling time, the stagnant water was removed. The crucibles were stored in the oven at $35^{\circ} \mathrm{C}$. The deposits were characterized using scanning electron microcopy (SEM), adsorption of nitrogen and adsorption of water through attenuated total reflection-infrared (ATR-IR) spectroscopy.

$S E M$. The deposits were imaged in order to assess the arrangement of the particles. A regular arrangement of the $1.16 \mu \mathrm{m}$ silica micro-sphere was observed, as shown in Fig. 1, together with a number of faults. The images suggest that the packing fraction of the deposit is lower than the packing fraction of equal spheres, that is $\simeq 0.74$, and much larger that the random close packing (0.63).

Adsorption of nitrogen. The adsorption of nitrogen molecules $N_{2}$ (the adsorbate) to the surface of silica (the adsorbent) creates a film and the amount of adsorbate on the adsorbent as a function of its pressure at constant temperature is usually described as an isotherm. The isotherm, shown in Fig. 2, was carried out at $77 \mathrm{~K}\left(-196.15^{\circ} \mathrm{C}\right)$ using a gas adsorption instrument (Belsorp-max from BEL Japan, Inc.) after outgassing the sample at $200^{\circ} \mathrm{C}$ 

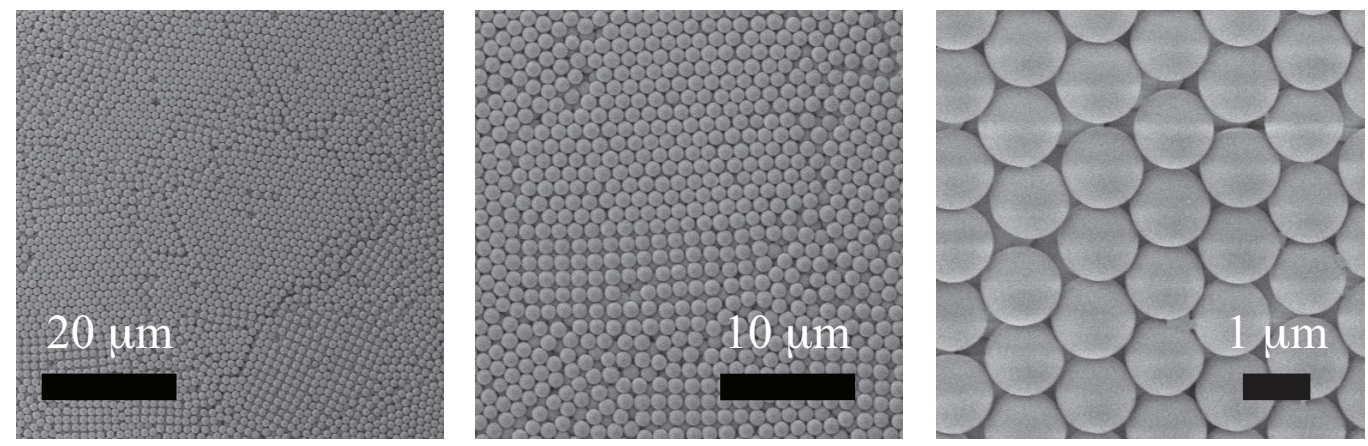

Figure 1: SEM images of an arrangement of silica micro-spheres of $1.16 \mu \mathrm{m}$ in diameter

for several hours. The sample was a $25.5 \mathrm{mg}$ deposit of colloidal silica of 179 $\mathrm{nm}$ diameter. The density of the colloidal silica is $2.2 \mathrm{~g} . \mathrm{cm}^{-3}$ [20]. Globally, the isotherms are typical of mesoporous or macroporous materials. There is a slight hysteresis at high pressures, close to saturation. The adsorption and desorption isotherms are then analysed using several methods: Langmuir method, BET method, $t$-plot method, BJH method or NLDFT method. The specific surface area is $24 \pm 2 \mathrm{~m}^{2} \cdot \mathrm{g}^{-1}$ and the mean pore diameter is $60 \pm 15$ $\mathrm{nm}$. The measured specific surface area is larger than expected from theoretical consideration of perfectly smooth mono-disperse spheres $\left(\simeq 15 \mathrm{~m}^{2} \cdot \mathrm{g}^{-1}\right)$, because of the faults described earlier and the roughness of the spheres.

Adsorption of water. Let's turn now to the adsorption of water at room temperature. At an atomistic level, an ice-like region forms close to the silica surface through roughly three monolayers. Above this ice-like region, there is a transition region whose structure is disordered as the liquid layers above it. A schematic is shown in Fig. 3(a). The adsorption-desorption of water molecules is studied using a specific technique, proposed by Asay and Kim [21], using attenuated total reflection-infrared (ATR-IR) spectroscopy signals at different relative humidities. Practically, a water drop of $1 \mu \mathrm{L}$ containing $5 \%$ silica micro-spheres of $179 \mathrm{~nm}$ is first dried for several hours on the diamond crystal surface of a spectrometer (Thermo Scientific Nicolet 6700 FT-IR with the Pike MIRacle ATR accessory). The dried deposit is enclosed in a box and there is a flow of nitrogen gas $\left(2-3 \mathrm{~mL} \cdot \mathrm{min}^{-1}\right)$. The relative humidity of the flow is controlled by the input of a mixture of dry nitrogen gas and water saturated nitrogen. The relative humidity was measured using a thermo-hydrometer (Hanna instruments) with a resolution of $\pm 5 \%$. The 


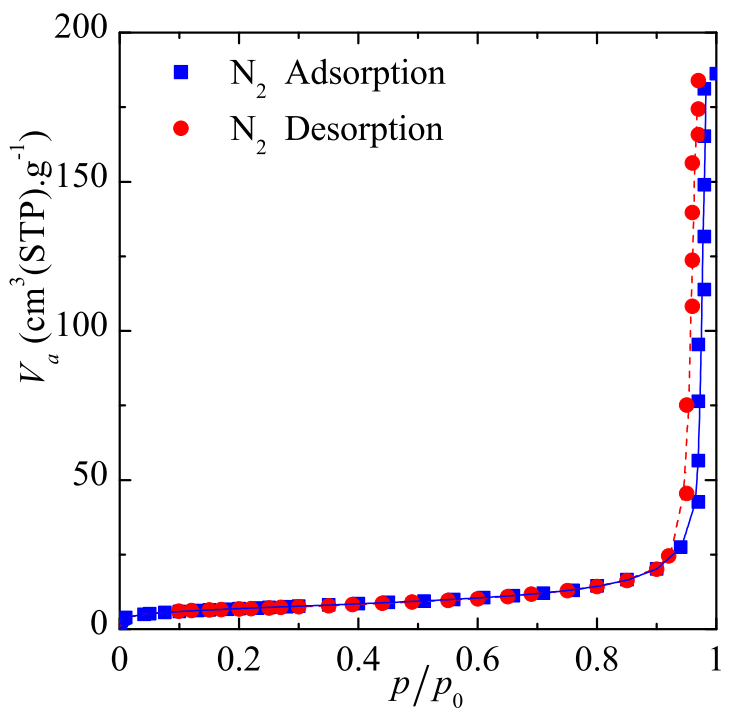

Figure 2: Nitrogen adsorption and desorption isotherms of a silica colloidal deposit made of mono-dispersed micro-spheres of $179 \mathrm{~nm}$ in diameter. The experiment was performed at $77 \mathrm{~K}$ and the lines represent NLDFT isotherm fits.

temperature of the system was maintained at $25 \pm 1^{\circ} \mathrm{C}$. In this analysis, the evanescent wave penetrates the deposited silica and the gas phase. The absorbed molecules are detected, enabling a vibrational spectroscopy study. There are two main adsorption bands: a first peak at $1650 \mathrm{~cm}^{-1}$ due to $\mathrm{H}-\mathrm{O}-\mathrm{H}$ bending vibration and a group of peaks at $3000-3700 \mathrm{~cm}^{-1}$ due to $\mathrm{O}-\mathrm{H}$ stretching vibrations. The area below the group of stretching peaks changes more significantly with relative humidity than the area below the bending peak. The peaks at 3250 and $3400 \mathrm{~cm}^{-1}$ correspond to stretching vibration of ice-like and liquid water, respectively [21]. Detailed information about the molecular structure of water can be obtained from the analysis of the absorbance peaks presented in Fig. 3(b). The basic assumption is that the adsorbed water on the silica surface grows proportionally to the peaks area and the absorbance results indicate that the stretching vibration of ice-like and liquid water are present at $30 \%$ relative humidity. As the relative humidity increases above $80 \%$, the thickness of the absorbed layer increases exponentially and bulk condensation is taking place. The numerical integration of the peaks in Fig. 3(b) at different relative humidity leads to a water adsorption isotherm shown in Fig. 4. The type of isotherm is consistent 
with previous results [22] where the effect of silanization and water adsorption kinetic were taken into account.

\section{Results and discussion}

Water evaporation and boiling within silica deposits was studied using calorimetry. First a series of drying experiments at temperatures above the boiling point is presented together with photomicrographs of the surfaces of the deposits. For membranes having cylindrical pores, no patterns were observed, whereas cracks and craters are found in dried particle deposits. Then a series of differential scanning calorimetry (DSC) experiments [23] indicate that the boiling within silica deposits caused two endothermic peaks: one at $100^{\circ} \mathrm{C}$ and a second at higher temperature. The second peak is confirmed by thermo-gravimetry analysis (TGA) and experiments using heptane as a working fluid.

\subsection{Isothermal drying at high temperatures}

Nešić and Vodnik [17] studied the evaporation of pendant water droplets containing colloidal silica. They measured simultaneously the weight and temperature of the colloidal silica droplets as a function of time in a steady stream of air at constant temperature. They confirmed the existence of a multi-stage temperature curve describing the evaporation kinetics.

In Fig. 5(a), a schematic of the evaporation kinetics of water from membranes having cylindrical pore is presented. The pores are associated with the diameter of the cylindrical holes. Clearly the evaporation in cylindrical pore is straightforward because it takes advantage of vent or chimney effect, whereas in deposits there are a number of restrictions or obstructions. Indeed, in the case of deposits, depicted in Fig. 5(b), the voids in the deposits have a range of dimensions associated to the complex morphology of the pores. Moreover, the rapid evaporation of liquid water is likely to entrain particles, which accumulate close to the liquid-vapour interface, and form aggregates. As water evacuates, vapour develops under the heated crust and pressure builds up until large cracks form.

In the following the preparation of the drying experiments is described. As explained before the silica micro-spheres sedimented into the crucible and the deposit slowly dried at low temperature forming a homogeneous surface. The experiment starts by adding water. The porous deposit absorbs the water in few seconds. Next, the crucible was closed and welded to a 

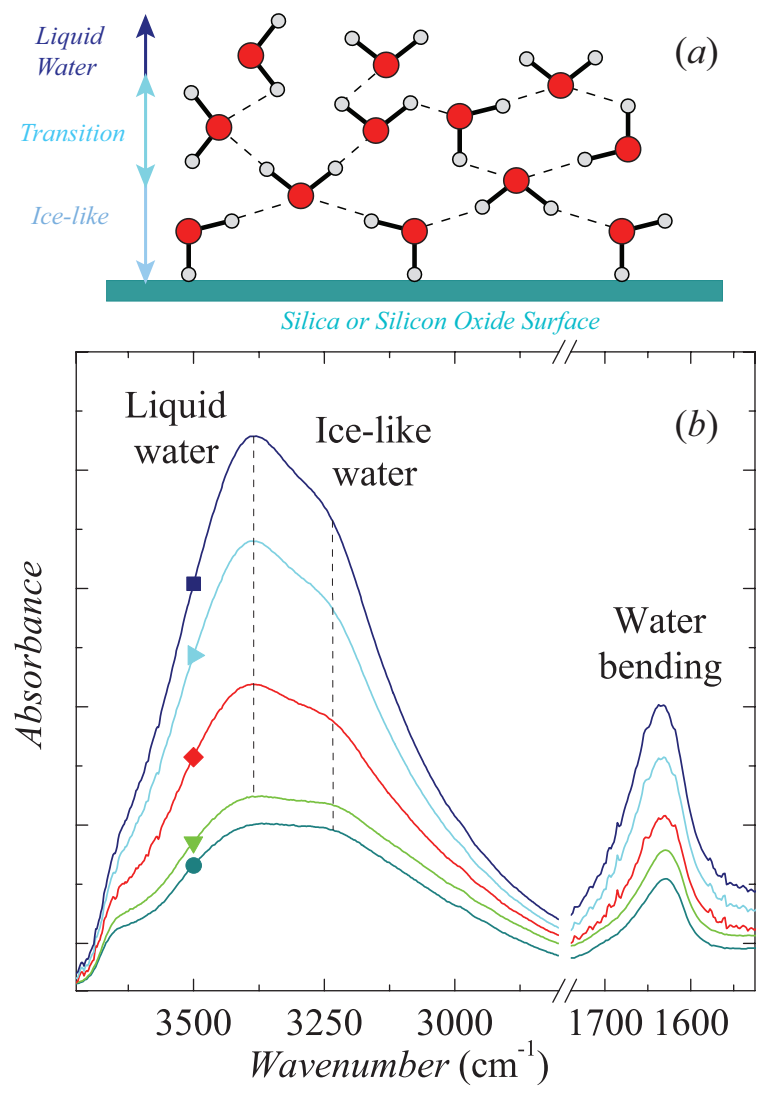

Figure 3: (a) Schematic, inspired from Asay and Kim [21], illustrating the structure of water molecules adsorbed on the silica surface. As the relative humidity increases, water adsorb in the liquid configuration - - - hydrogen bonds, - covalent bonds. (b) ATR-IR spectra of water absorbed on silica at different relative humidities. From bottom to top, relative humidity equals $30,80,90,94$ and $96 \%$. The $\mathrm{O}-\mathrm{H}$ stretching vibration peak of ice-like water and liquid water are indicated by vertical dashed lines at 3200 and 3400 $\mathrm{cm}^{-1}$. 


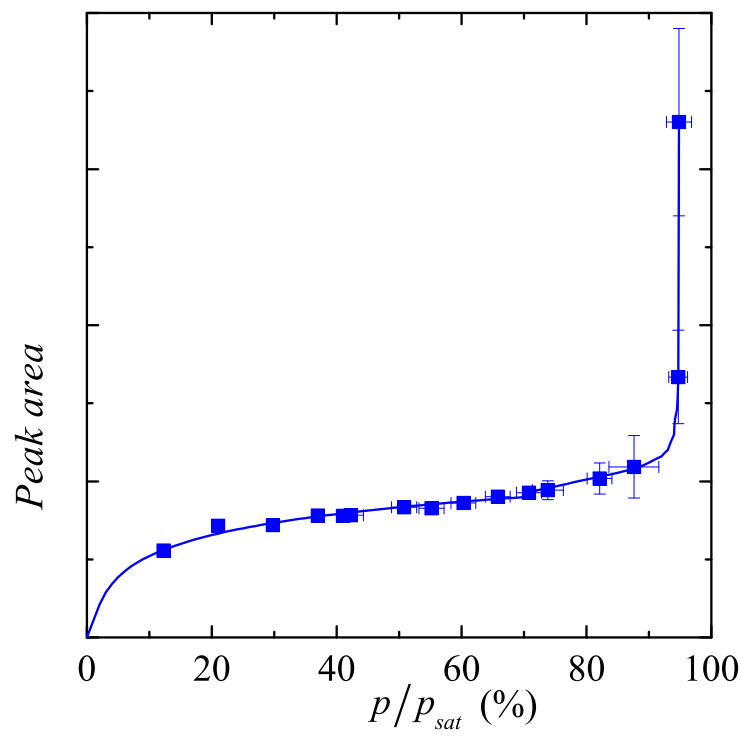

Figure 4: Adsorption isotherm of water on silica surface. Square symbols represent the adsorbed water from the area of the bending and stretching vibration peaks. The error bars represent the variation over two runs of the experiment. The solid line is drawn to guide the eyes. The experiment was performed at $25^{\circ} \mathrm{C}$.

perforated aluminium lid with a top hole of $50 \mu \mathrm{m}$. The effect of the lid is to locally increase the vapor pressure over the sample and control the influence of the surrounding flow. The samples are weighed before and after the run in order to confirm the evaporation. The calorimeter (DSC 822e from Mettler-Toledo) was used under a steady stream of nitrogen $\left(80 \mathrm{~mL} \cdot \mathrm{min}^{-1}\right)$.

In addition to the tests with the deposits, experiments were also conducted using membranes having cylindrical pores and particle deposits. The membranes (Anodisc 25 from Whatman) are made of aluminum oxide and had cylindrical pores of $0.2 \mu \mathrm{m}$ in diameter over a thickness of $60 \mu \mathrm{m}$. The membranes weighed $11 \pm 1 \mathrm{mg}$. The deposits described before were made of $1.16 \mu \mathrm{m}$ diameter micro-spheres and the sample weighed $19.6 \pm 0.4 \mathrm{mg}$. Given the size of the crucible, the stack of micro-sphere is about 500 layers and the total volume available within the pores is $0.5 \mathrm{~mL}$. Initially, the deposit is filled with $10 \mathrm{~mL}$ of water and consequently a liquid film covers the deposit. At $t=0$, the sample is inserted in the pre-heated calorimeter. Isothermal measurements provide a direct insight into the kinetics of the drying. In Fig. 5(c), the evolution of four typical runs of the drying of membranes are 

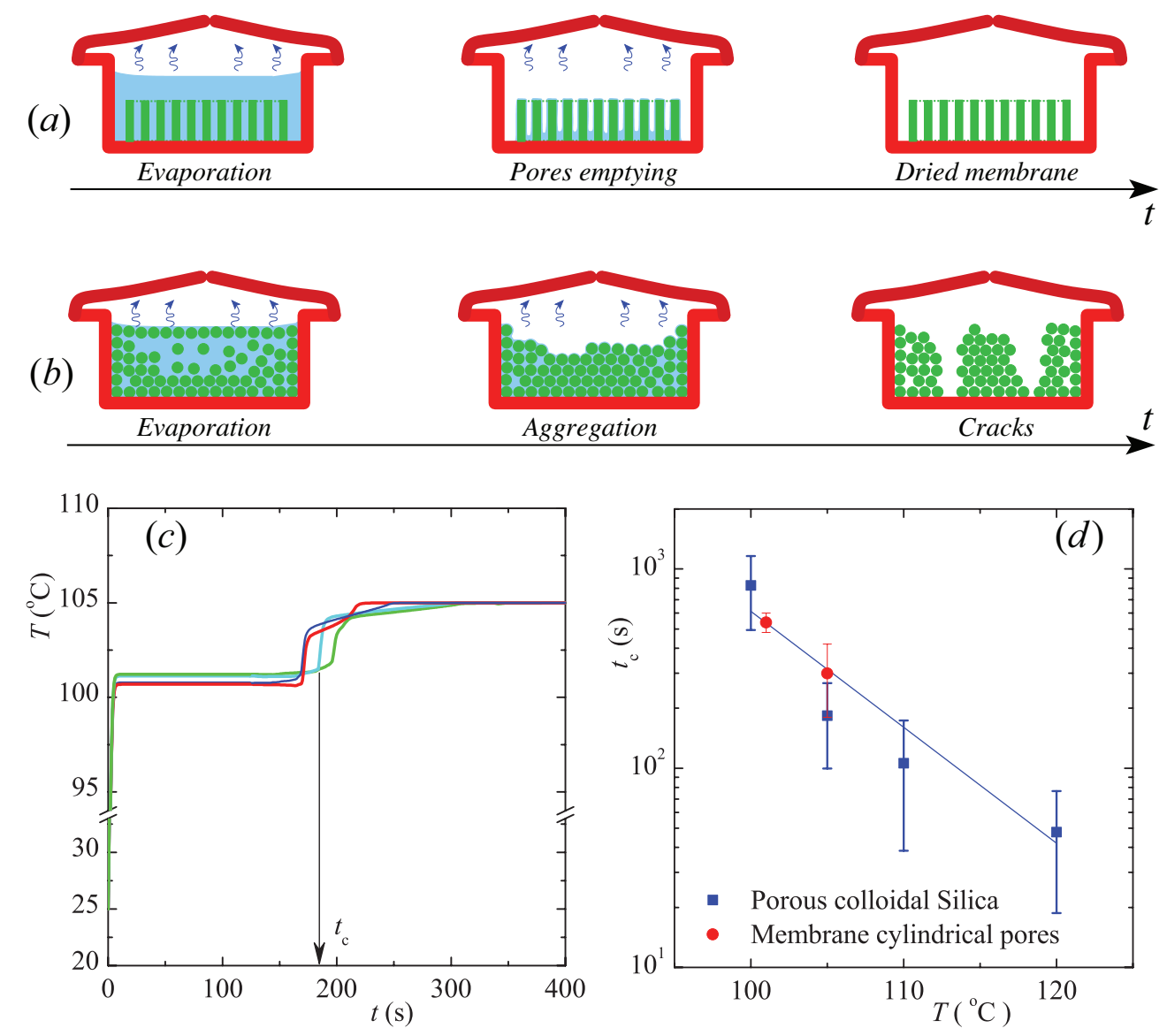

Figure 5: (a) Schematics of the evaporation kinetics of a water imbibed membrane. $(b)$ Schematics of the drying kinetics of colloidal silica deposit. (c) Evolution of the temperature of a drying membrane imbibed in water at $105^{\circ} \mathrm{C}, t_{c}$ defines the critical time and the different curves correspond to the results obtained for different runs. $(d) t_{c}$ versus the drying temperature. The error bars represent the standard deviation based on 3-4 runs of the experiment and the line is a power law fit of the data. 


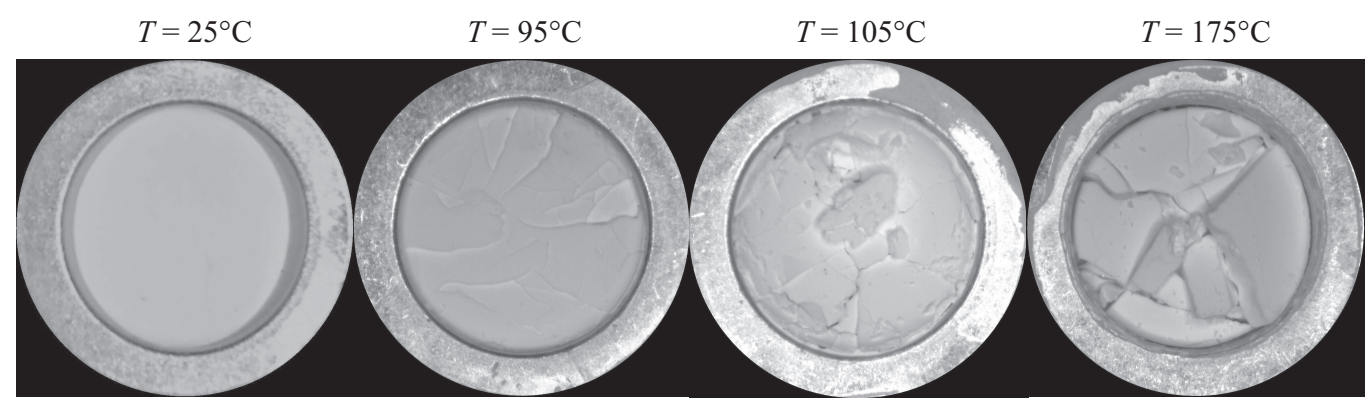

Figure 6: Micrographs of cracked patterns after drying of silica crystal of deposits of about 500 layers of $1.16 \mu \mathrm{m}$ diameter micro-spheres. The deposits were prepared in aluminium crucibles of $5 \mathrm{~mm}$ inner diameter.

presented. The temperature increases from $25^{\circ} \mathrm{C}$, reaches a plateau and then at a critical time $t_{c}$ there is a sharp increase in temperature until the final temperature of the calorimeter. For drying temperatures above $100^{\circ} \mathrm{C}$ the critical time, $t_{c}$, decreases rapidly, as indicated in Fig. $5(d)$.

During drying, the dominant stress is the capillary pressure from the tiny menisci between particles:

$$
\Delta P=2 \sigma \cos \theta / r
$$

where $\sigma$ is the surface tension coefficient, $\theta$ is the solvent-particle contact angle and $r$ is the radius of curvature which is typically $r \approx 0.1 R$ for randomly close-packed spheres of radius $R$. The radius of the meniscus, $r$, can be obtained from the Kelvin equation provided that the saturation vapor pressure is known. Since $\sigma \simeq 72 \mathrm{mN} \cdot \mathrm{m}^{-1}$ and $\cos \theta \approx 1$, the capillary pressure: $\Delta P \approx 6 \times 10^{5} \mathrm{~Pa}$ or $6 \mathrm{~atm}$ for $d=1.16 \mu \mathrm{m}$ particles. Relative to the ambient pressure surrounding the droplet, the liquid within the pores has a lower pressure. Therefore every meniscus acts like a low pressure pump trying to suck liquid from other places. Also liquid flow may be able to move particles around.

In figure 6, the dried silica deposits are observed under an optical microscope. The smooth surface observed on the deposit at $25^{\circ} \mathrm{C}$ is the initial pattern before adding water and running the experiment. As the drying temperature increases (i.e. $95^{\circ} \mathrm{C}$ ), there is the formation of cracks. At higher temperature $\left(105\right.$ and $\left.175^{\circ} \mathrm{C}\right)$, craters are observed.

There are several possible scenarios describing the drying. In a first scenario, the craters are due to the vapor accumulated underneath the deposit, 
which was able to form large bubbles. These vapor bubbles are about 1600 times less dense that the deposit. The vapor rapidly accumulated and grew below or within the deposit. Its expansion is important and the force associated to the buoyancy are sufficient to crack the deposit and create craters. In a second scenario, a drying front travels from the upper surface through the deposit towards the crucible. In this case the cracks would be formed by the capillary pressure.

It is important to note that in the case of membranes, no visual defects were observed.

\subsection{Scanning experiments}

Let's look now at the temperature scanning experiments. The usual experiment in DSC consists in measuring both the sample and a reference temperature. The difference of heat required to increase the temperature of the sample and the reference is measured as a function of temperature. More of less heat must flow into the sample depends on the nature of the process. For example, as water evaporates and boils from a sample it will require more heat flowing into the sample to maintain its temperature constant. This process is endothermic. A single evaporation peak is observed in Fig. 7 when increasing temperature with a rate of 0.75 and $10 \mathrm{~K} \cdot \mathrm{min}^{-1}$ and after adding various quantities of water to the cylindrical pore membrane. The width and the area of the peak is proportional the quantity of water added. The right side of the peak is sharp indicating the abrupt emptying of the pores.

In the case of a deposit of $1.16 \mu \mathrm{m}$ silica micro-sphere, there is a first peak at $100^{\circ} \mathrm{C}$, as showed in Fig $8(a)$. More importantly, a second peak is observed around $120^{\circ} \mathrm{C}$, which seems to correspond to the desorption of confined water. This second paek was also observed for deposit of smaller particle of $127 \mathrm{~nm}$. The position of the minimum of the second peak changes with the scanning rate (see inset in Fig 8(a)) suggesting a transient delay of the boiling of the water in the pores.

Another scanning experiment at a heating rate of $5^{\circ} \mathrm{K} \cdot \mathrm{min}^{-1}$ was carried out using a TGA where the weight loss was measured using a microbalance. Again the $1.16 \mu \mathrm{m}$ silica deposit experiences a second peak, which water content corresponds to $5 \%$ of the evaporated water. This measurement confirms that the secondary peak corresponds to a weight loss.

Additional experiments using heptane, $\mathrm{C}_{7} \mathrm{H}_{16}$, were conducted. Heptane was chosen because its boiling temperature of $98.61^{\circ} \mathrm{C}$ close to the boiling temperature of water. However, the density of heptane is $680 \mathrm{~kg} \cdot \mathrm{m}^{-3}$; also 


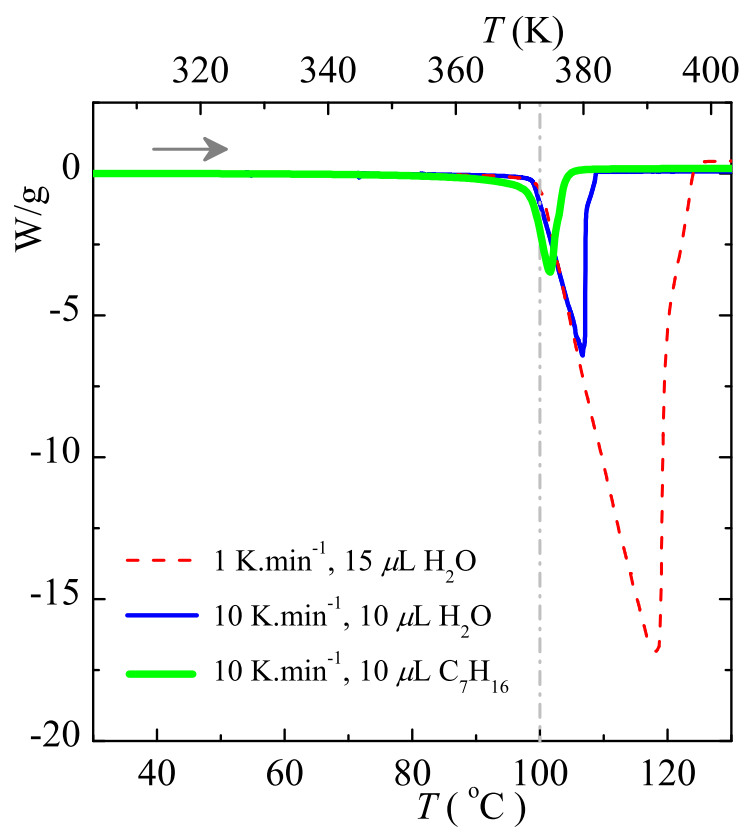

Figure 7: DSC results for water and heptane imbibed membranes having cylindrical pores at different heating rates
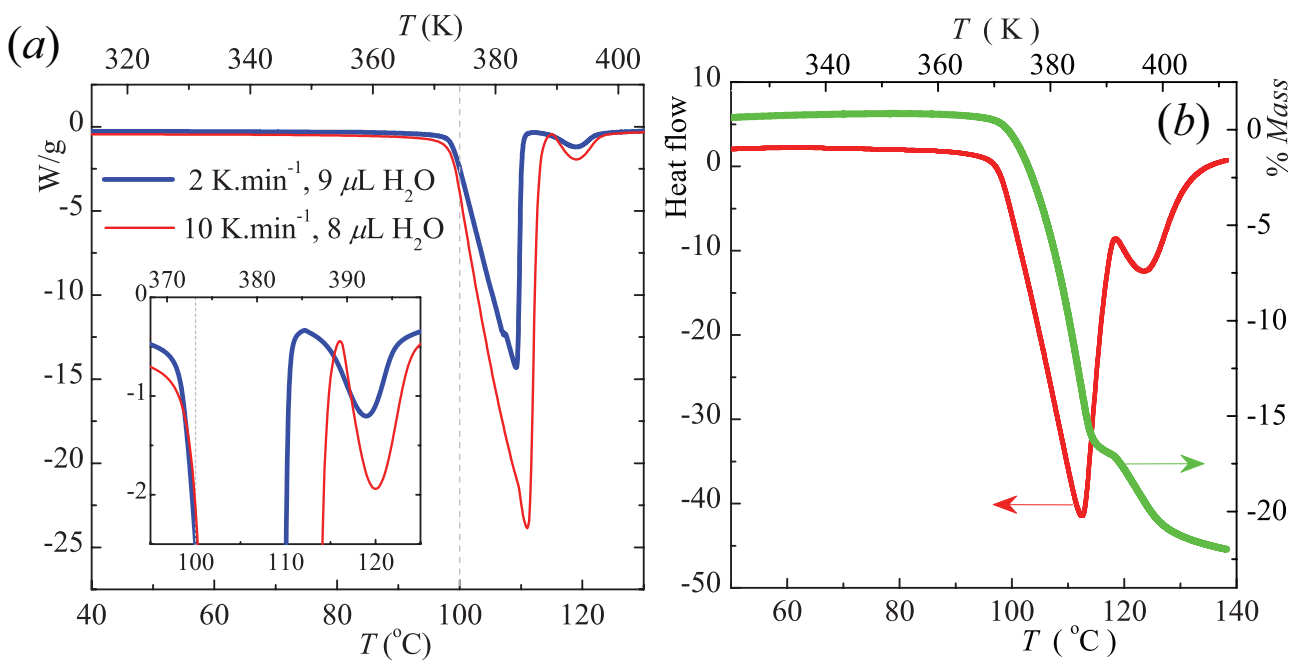

Figure 8: (a) DSC curves of $1.16 \mu \mathrm{m}$ deposits showing the energy versus the temperature for different scanning rates. The inset is a magnification of the second peaks. (b) TGA curves showing the energy and weight loss versus the temperature. 


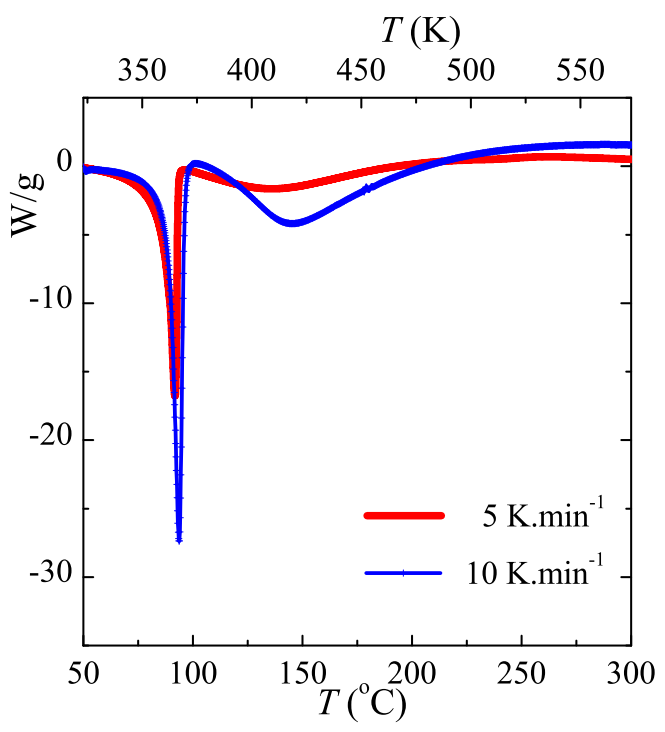

Figure 9: DSC curves showing the energy versus temperature for different heating rates. The deposit is about 500 layers of colloidal silica $(1.16 \mu \mathrm{m})$ imbibed in $10 \mu \mathrm{L}$ of heptane.

the wetting properties are different from that of water: the surface tension coefficient is $20 \mathrm{mN} \cdot \mathrm{m}^{-1}$ and the contact angle with silica is $40^{\circ}$. In the case of heptane, DSC scanning runs indicate that the area under the secondary peak equals that of the first peak. In Fig. 9, the second peak is centered around $140^{\circ} \mathrm{C}$. The fact that the second peak is observed, both for water and heptane in colloidal deposits, whereas it is not seen in the case of membranes, suggests that the morphology of the deposits is responsible for the secondary desorption. The secondary peak for heptane is wider indicating that the water surface, the wetting and the buoyancy properties have an effect on the secondary release. As said before, the dominant stress during evaporation, is the capillary pressure from the tiny menisci between particles. These menisci move through the deposit at variable speeds depending on the properties of the fluids and the morphology of the deposit. These motions induce delays in the evaporation and it is suggested that the secondary peak is due to such kinetic effect. Another hypotheses is that the flow in the porous deposit induces particle motions and deformations of the material which delays the secondary desorption.

The measure of temperature differences between the sample and the reference is proportional to the phase transition enthalpies. This allows to detect 
endo or exo-thermic transitions. For water $\Delta H_{v a p}=1936 \pm 210{\mathrm{~J} . g^{-1}}$ (NIST

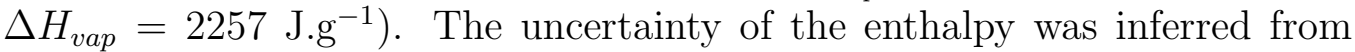
four repeated measurements. For heptane $\Delta H_{\text {vap }}=368 \pm 60 \mathrm{J.g}^{-1}$ (NIST

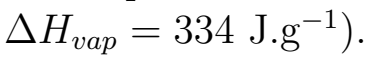

The liquid-vapour phase transition of water in porous materials has also been observed using DSC and TGA in order to obtain both boiling temperature and vaporization heat $[24,25]$. Two studies used DCS and TGA to investigate boiling on porous materials $[26,27]$. They found a double peak corresponding to the desorption of the fluid from the material and it is suggested the physicochemical properties of surface water are responsible from the peak. However no information is given on the final state of the material.

Eventually, boiling point elevation was not observed in the present calorimetric measurements because the pore here are large. Indeed, boiling point elevation was observed in a sample of silica MCM-41 mesoporous [28] where water in $2 \mathrm{~nm}$ diameter pore material experiences boiling at $390 \mathrm{~K}\left(116.8^{\circ} \mathrm{C}\right)$.

\section{Conclusion}

The evaporation and boiling of water in deposits of silica micro-spheres were studied. The deposits were characterised using scanning electron microscopy, adsorption of nitrogen, and adsorption of water through attenuated total reflection-infrared spectroscopy. Initially the deposits made of monodispersed micro-sphere are regularly ordered together with a number of faults. A number of drying experiments were carried out using differential scanning calorimetry and thermal gravimetric analysis. It has been found that the desorption of water in deposits is a two step process. The bulk water evaporates first, then the desorption of water within the pore takes place at higher temperature $\left(125^{\circ} \mathrm{C}\right)$ when the heating rate is 1 to $10 \mathrm{~K} \cdot \mathrm{min}^{-1}$.

Interestingly the final deposit pattern films were also observed using optical microscopy and cracks appear on the surface of the dried silica. The cracks were observed at drying temperature below the boiling temperature. At larger temperatures, craters are observed indicating that vapor bubbles formed underneath the deposit and travelled through the deposit.

The results are compared with water evaporating from membranes having cylindrical pores and for heptane. In the case of cylindrical capillaries, no second peak and no cracks or deformation of the membrane is observed. When the fluid is heptane, the secondary peak is wider and shifted meaning 
that the wetting and density of the liquid (Bond number) have also an effect on evaporation in deposits.

\section{Acknowledgments}

This research is supported by EDF. We are grateful to Alexander Neimark (Rutgers University) for discussions regarding adsorption measurements and Philippe Vermaut (LPCS, Chimie-ParisTech and CNRS) for discussions regarding the DSC experiments.

\section{References}

[1] H. Chang, Endeavour 31(1) 7-11 (2007)

[2] L. Cerovic, G. Lefèvre, A. Jaubertie, M. Fedoroff, S. Milomjic, J. Colloid Interface Sci. 330284 (2009)

[3] C. Henry, J.-P. Minier, G. Lefèvre, O. Hurisse, Langmuir 27(8) 4603 (2011)

[4] S.J. Green, G. Hetsroni, Int. J. Multiphase Flow 211 (1995)

[5] C. Faivre, D. Dellet, G Dolino, Eur. Phys. J. B 719 (1999)

[6] A. Schreiber, I. Ketelsen, G.H. Findenegg, Phys. Chem. Chem. Phys. 3 1185 (2001)

[7] H.K. Christenson, J. Phys.: Condens. Matter 13 R95 (2001)

[8] M. Kaviany, Principles of heat transfer in porous media, Springer (1995)

[9] D. Stemmelen, P. Dominiak, C. Moyne, Int. J. Therm. Sci. 38572 (1999)

[10] J. Benard, R. Eymard, X. Nicolas, C. Chavant, Transp. Porous Med. 60 $1(2005)$

[11] A. Sahli, C. Moyne, D. Stemmelen, Transp. Porous Med. 82527 (2010)

[12] E. Kierlik, F. Leoni, M.L. Rosinberg, G. Tarjus, Mol. Phys. 109 11431157 (2011) 
[13] R.J.-M. Pellenq, B. Rousseau, P.E. Levitz, Phys. Chem. Chem. Phys. 3 1207-1212 (2001)

[14] R.K. Iler, The chemistry of silica: solubility, polymerization, colloid and surface properties and biochemistry of silica, Wiley-Interscience (1979)

[15] K.B. Singh, M. Tirumkudulu, Phys. Rev. Lett. 98218302 (2007)

[16] T. Okudo, J. Okamoto, A. Tsuchida, Colloid. Polym. Sci. 285 1247-1255 (2007)

[17] S. Nesic, J. Vodnik, Chem. Engng. Sci. 46 527(1991)

[18] M. Mezhericher, A. Levy, I. Borde, Chem. Engrg. Sci. 63 12-23 (2008)

[19] C.S. Handscomb, M. Kraft, A.E. Bayly, Chem. Engng. Sci. 64 628-637 (2009)

[20] D.R. Lide, Handbook of Chemistry and Physics, $79^{\text {th }}$ Edition, CRC Press (1998)

[21] D.B. Asay, S.H. Kim, J. Phys. Chem. B 10916760 (2005)

[22] T.M. Muster, C.A. Prestidge, R.A. Hayes, Colloids Surf. A: Physicochem. Eng. Aspects 176 253-266 (2001)

[23] G.W.H. Höne, W.F. Hemminger, H.-J. Flammersheim, Differential scanning calorimetry, Springer (2003)

[24] F.M. Etzler, J.J. Conners, Thermochim. Acta 189 185-192 (1991)

[25] F.O. Cedeno, M.M. Prieto, A. Espina, J.R. Garcia, J. Therm. Anal. Calorim. 73 775-781 (2003)

[26] P. Staszczuk, M. Jaroniec, R. K. Gilpin, Thermochim. Acta 287 225-233 (1996)

[27] Q.S.M. Kwok, D.E.G. Jones, J. Therm. Anal. Calorim. 74 57-63 (2003)

[28] E.W. Hansen, R. Schmidt, M. Stocker, in Progress in zeolites and microporous materials edited by H. Chon, S.-K. Ihm and Y.S. Uh 105 543-550 (1997) 